\title{
Emerging Business Trends in the Microelectronics Industry
}

\author{
Samar K. Saha \\ Prospicient Devices, Milpitas, USA \\ Email: samar@ieee.org
}

Received 10 December 2015; accepted 16 January 2016; published 19 January 2016

Copyright (C) 2016 by author and Scientific Research Publishing Inc.

This work is licensed under the Creative Commons Attribution International License (CC BY). http://creativecommons.org/licenses/by/4.0/

(c) (i) Open Access

\begin{abstract}
This paper describes the emerging trends in the major business segments of the integrated circuit industry. As the integrated circuit technology approaches its ultimate scaling limit, the different segments of the industry are evolving continuously by adopting new business strategies to gain competitive advantage: the manufacturing is persistently releasing next generation technologies, dedicated foundries are transitioning to complete product development solution providers, fabless companies are adopting innovative business strategies, integrated device manufacturers are transitioning to fab-lite, and the assembly and test is developing scaled packages. This paper discusses the evolution of these major business segments in the microelectronics industry.
\end{abstract}

\section{Keywords}

Microelectronics Industry, Integrated Device Manufacturers, Semiconductor Foundry, Fabless Business, Fab-Lite Business, Emerging Business Model, IoT, Smart City, Smart Cars

\section{Introduction}

The semiconductor industry in general and the microelectronics sector in particular have been continuously evolving since the invention of integrated circuits (ICs) in the year 1958 [1] [2]. The multitrillion dollar microelectronics industry is fundamentally dependent on the development, manufacturing, and sales of semiconductor ICs. Throughout the 1960s, the IC business was dominated by bipolar junction transistor (BJT) technology [3]. The 1970s evidenced the metal-oxide-semiconductor (MOS) field-effect transistor (MOSFET) technology beginning to overtake the BJT technology in terms of the functional complexity and level of integration. And, consequently, the complementary MOS (CMOS) technology with its cost-effective technology solution became the pervasive technology for ICs since 1980s [3]. From the mid-1970s, the integrated device manufacturers (IDMs) have been continuously developing a new generation IC fabrication technology in about every two years 
by aggressively scaling down MOSFET devices to improve IC performance at a reduced cost as predicted by Moore's Law [4]. However, with the continuous scaling of MOSFETs, the transistor dimensions are rapidly approaching to their ultimate physical limit. As a result, the development of advanced CMOS technology in accordance to Moore's Law has been slowed down significantly in recent years.

In the 1980s, IDMs achieved competitive advantage through in-house manufacturing at the firm's own IC fabrication facilities (fabs). However, with the emergence of foundry business model in 1987 by Morris Chang [5], the new business trends have emerged in the IC industry separating design and manufacturing and establishing fabless design houses and "dedicated foundries," hereafter, referred to as the "foundries" [6]-[9]. The foundry business model established a new way of gaining competitive advantage by the IC companies without multi-billion dollar capital investments to set up manufacturing fabs [10]-[13]. The "pure-play" foundries provide manufacturing solution to fabless companies for their products. Gradually, most of the IDMs, except a few like Intel and Samsung, started outsourcing manufacturing to the dedicated foundries and became "fab-lite" [14]. The foundry business model offers IC design companies easier market entry to design and sale niche products and set new business trends in the microelectronics industry [10]-[13]. In order to provide manufacturing solution, the dedicated foundries develop advanced manufacturing technology [15] [16] whereas fabless companies focus in design and new product development. Thus, the separation of design and manufacturing has commoditized IC manufacturing technology, referred to as the "front-end" technology [14].

With the commoditized front-end manufacturing technology and slowed down pace of advanced technology development, new trends are emerging in different segments of the microelectronics industry. Due to commoditized technology, the back-end processing (assembly and test) has become very critical to provide high performance IC chips. And, therefore, the leading semiconductor assembly and test companies are developing capabilities to offer miniaturized or scaled packaging solutions of ICs to their customers. Since the progress predicted by Moore's Law has slowed down in many segments of the IC industry compared to that in the early days of IC manufacturing, new business trends are evolving in the above described segments of the industry to compete in the global market.

The objective of this paper is to present the emerging trends in the major business segments of the microelectronics industry. In order to achieve this goal, first of all, we describe the foundry business model and changes occurring in the fabless segments of the microelectronics industry. Then, we analyze the front-end fabrication segment of the industry that is continuing to drive technology development thus, enabling the kind of advances predicted by Moore's Law. Finally, we introduce the back-end fabrication segment where the miniaturization race seems to be shifting assembly-and-test segment of the microelectronics industry.

\section{Emerging Trends in the IC Industry}

Since the emergence of the foundry business model, the microelectronics industry is continuously evolving. The foundry business model is the main driver for the vertical disintegration of the front-end manufacturing and chip design as shown in Figure 1. As a result, a large number fabless microelectronics companies continue to emerge [11]-[14]. And, recently, the new trends are emerging in the foundry business, fabless segments, IDMs, and front-end and back-end manufacturing [17]. Some of these evolving trends in these four major business segments of the IC industry that are transitioning the industry are described in Sections $2.1-2.4$ below.

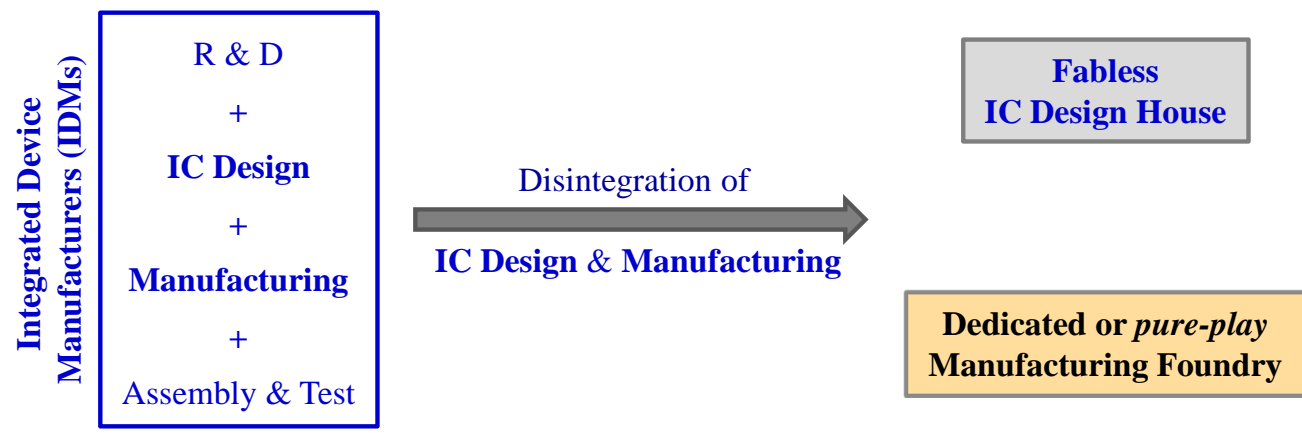

Figure 1. Vertical Disintegration of the of the integrated device manufacturers (IDMs) creating fabless IC design house and pure-play foundry business model in the microelectronics industry. 


\subsection{Foundry Business Model}

The IC foundry business is driven by fabless companies. In the conventional, "pure-play” manufacturing only, foundry business model, the foundries [6]-[9] provide only wafer fabrication services to their customers as shown in Figure 2(a). However, with the increase in the complexities and cost of system-on-chip (SoC) design, the emerging trends in the foundry business model is to providing complete manufacturing solutions to fabless companies [10]-[13].

Typically, the fabless companies design advanced products using third party electronic design automation (EDA) tools in-house and outsource front-end manufacturing to foundries and packaging to dedicated back-end manufacturing vendors to assemble the final products. Due to the increase in the cost and complexities of SoC design, the fabless companies, also, outsource design activities to vendors or corporate partners as shown in Figure 2(a) [13]. Thus, in order to take advantage of this tremendous business opportunity, some of the foundries are transitioning to complete IC new product development solution providers to their customers [10]-[13]. In this business model, the foundries provide necessary new product development support to their customers including chip design, layout design and verifications, process customization, manufacturing, wafer test, assembly and test, and logistics for on time delivery of final chips to fabless companies as shown in Figure 2(b) [10]-[13].

The transition of a foundry to a complete new product development solution provider is achieved by acquiring the necessary core competencies and product development technologies (PDTs) in-house [7] [10]-[13] or establishing partnership with different foundries or vendors with complementary competencies [9] [18]. The additional core competencies required to support customers' new product development include expertise in complex SoC design, technology customization, product testing and characterization, and packaging [11]-[13]. The major PDTs include [11]-[13] [19] [20]:

- Technology computer-aided-design (CAD) software;

- Modeling and characterization hardware and software;

- CAD tools for circuit analysis and design such as process-design-kit;

- Semiconductor Assembly and Test infrastructure.

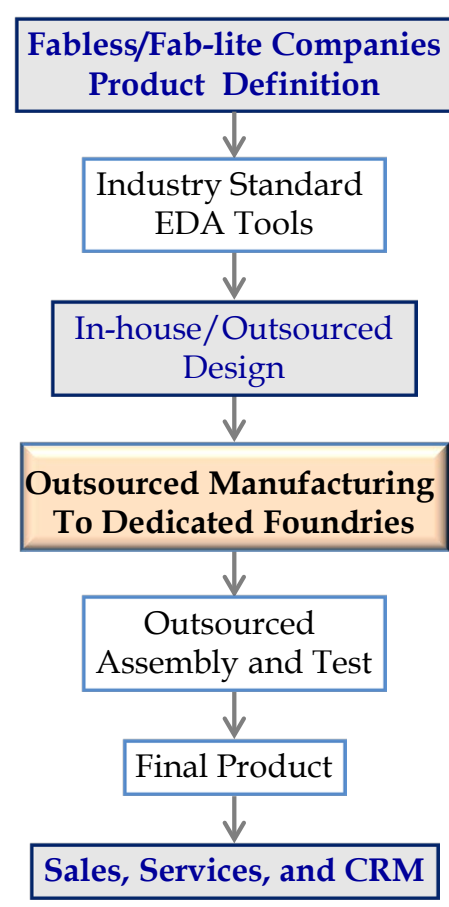

(a)

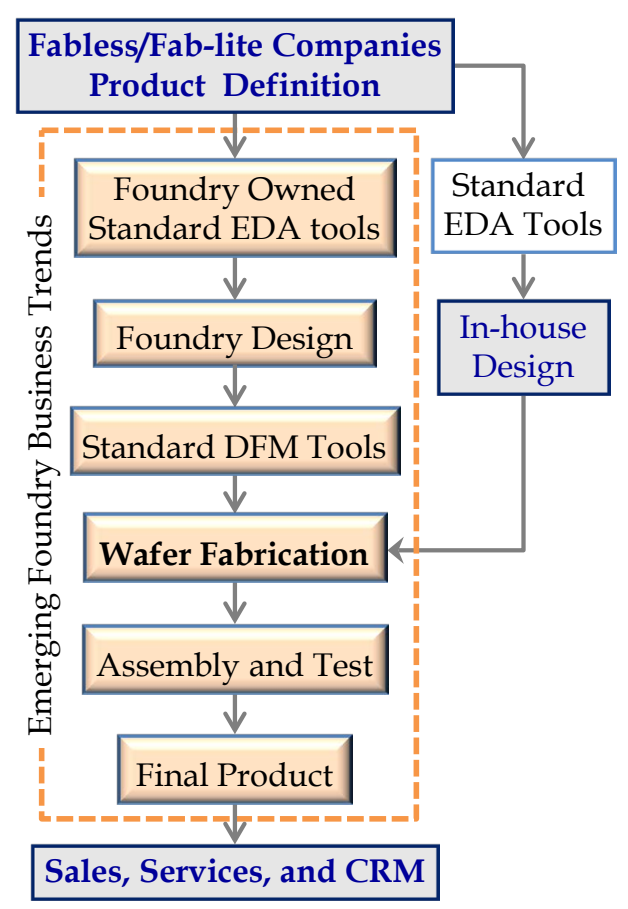

(b)

Figure 2. Foundry business model then and now: (a) early "pure-play" manufacturing only foundry operation; (b) emerging trends in the foundry business showing foundries as complete IC product development solution providers. (DFM refers to design for manufacturing and CRM refers to customer relationship management). 
In-house competency in Technology CAD is crucial to support technology development and technology customization, device characterization and modeling are critical for generating accurate models for SoC design, and Semiconductor Assembly and Test capabilities are critical to offer customers introducing new products within the "strategic window" of marketing. The detailed description of PDTs such as Technology CAD, characterization and modeling, and circuit CAD has been reported by Saha [11]. The advanced foundries are transitioning by acquiring core competencies in all the relevant areas of PDT to support fabless customers' manufacturing as well as new product development [11]-[13].

The core competencies described above are organized in a dedicated customer support team described as the PDT group (PDTG) [11]-[13] as shown in Figure 3. The functionalities of each PDT are set in different subgroups with ultimate objective of efficient customer support and customer relationship management. The inner-circle of Figure 3 shows the core competencies of PDTG whereas the outer circle shows PDTG establishing an extensive partnership network for "research and development" and information flow. The PDTG supports in-house technology development and characterization. It provides design and manufacturing solutions to customers, develops and maintains intellectual properties, and manages relationship with vendors, corporate partners, and academia for research and development of emerging technologies and products. Thus, in the foundry business model, the PDTG plays a critical role to support in-house technology development, provide complete new product development solutions to customers, and establish a link to the outside world for information flow and feedback as shown in Figure 3. The critical role of PDTG to support complete IC new product development is reported in the literature [11]-[13]. The PDTG is an important organization in the transitioning foundry business model from the pure-play manufacturing only to turn-key new product development solution provider in the microelectronics industry.

In the longer term, the foundry business has evolved over the last two decades. New 2015 Foundry Almanac by GSA and IC insights reports 37\% of IC sales now come from foundry capacity. Although earlier it competed on factor cost advantages, productivity gains, and operational excellence, it now depends on true technology leadership, scale advantages, and superior ecosystem for product design as shown in Figure 2(b) [16] [17].

\subsection{Fabless Business Model}

The foundry business model provides fabless companies an easy market entry with limited capital investment. As a result, new fabless IC companies with innovative product ideas are continuously emerging [21]. In recent years, fabless companies have continued to gain ground, outpacing IDMs as shown in Figure 4 and claiming more than $25 \%$ of the global market share as shown in Figure 5. Figure 4 shows the percentage change in IC sales each year during the years 2000-2014. It is seen from Figure 4 that the revenues for the fabless chip makers grew 8\% in the year 2014 compared to that of 7\% for IDMs showing the strength of the fabless segment in the last 14 years. It is observed from Figure 5 that in the year 2014, fabless IC company sales represent about 30\% percent of total worldwide IC sales, up from only about $8 \%$ in the year 2000 . And, assuming the same continued

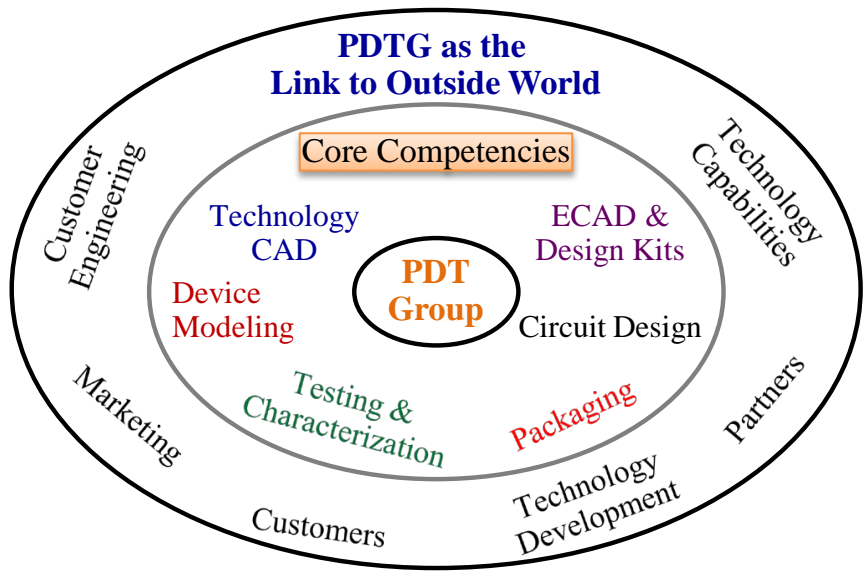

Figure 3. Integrated customer support team, PDTG to support different emerging roles of a transitioning foundry in providing complete IC product development solution provider. 


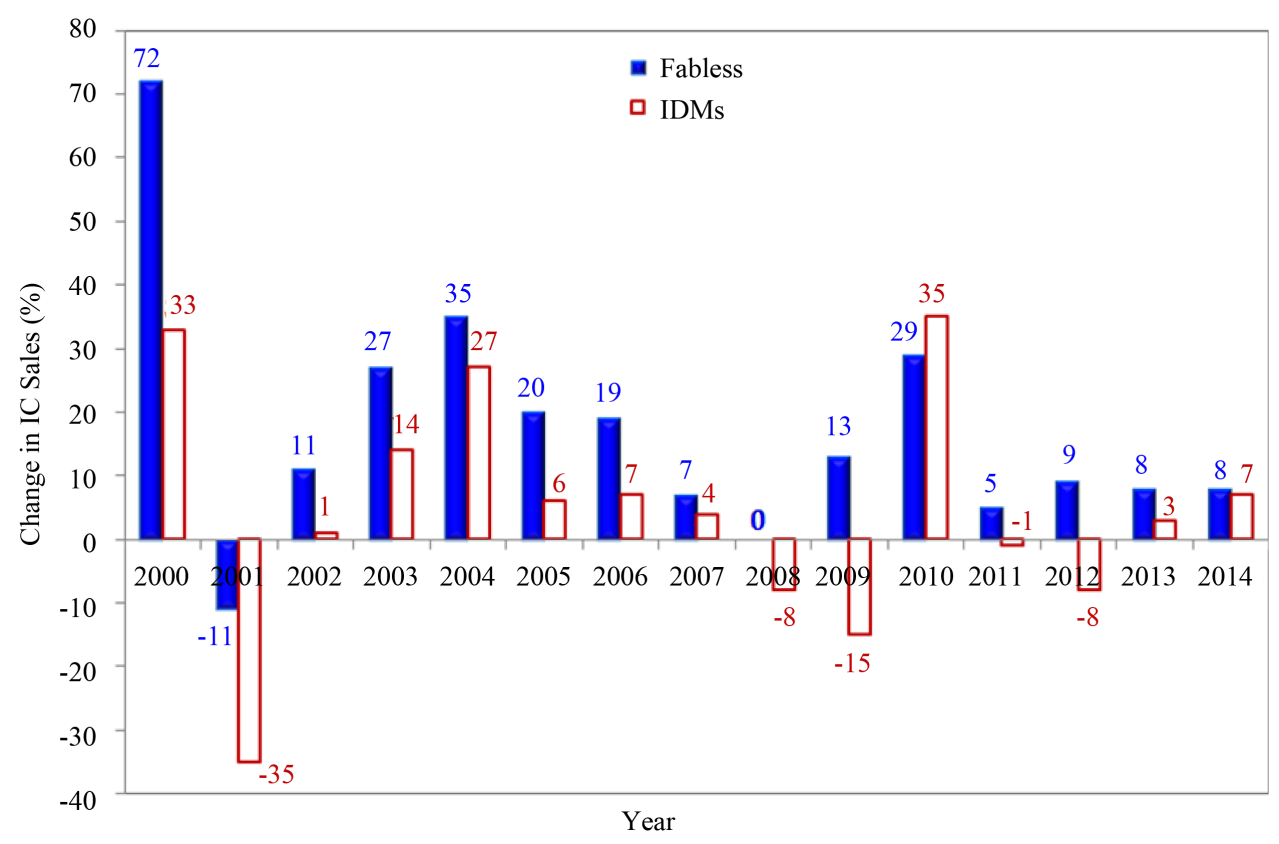

Figure 4. Fabless versus IDMs IC sales during 2000-2014 showing the historical trend of fabless companies performed much better than in every year; data obtained from [21].

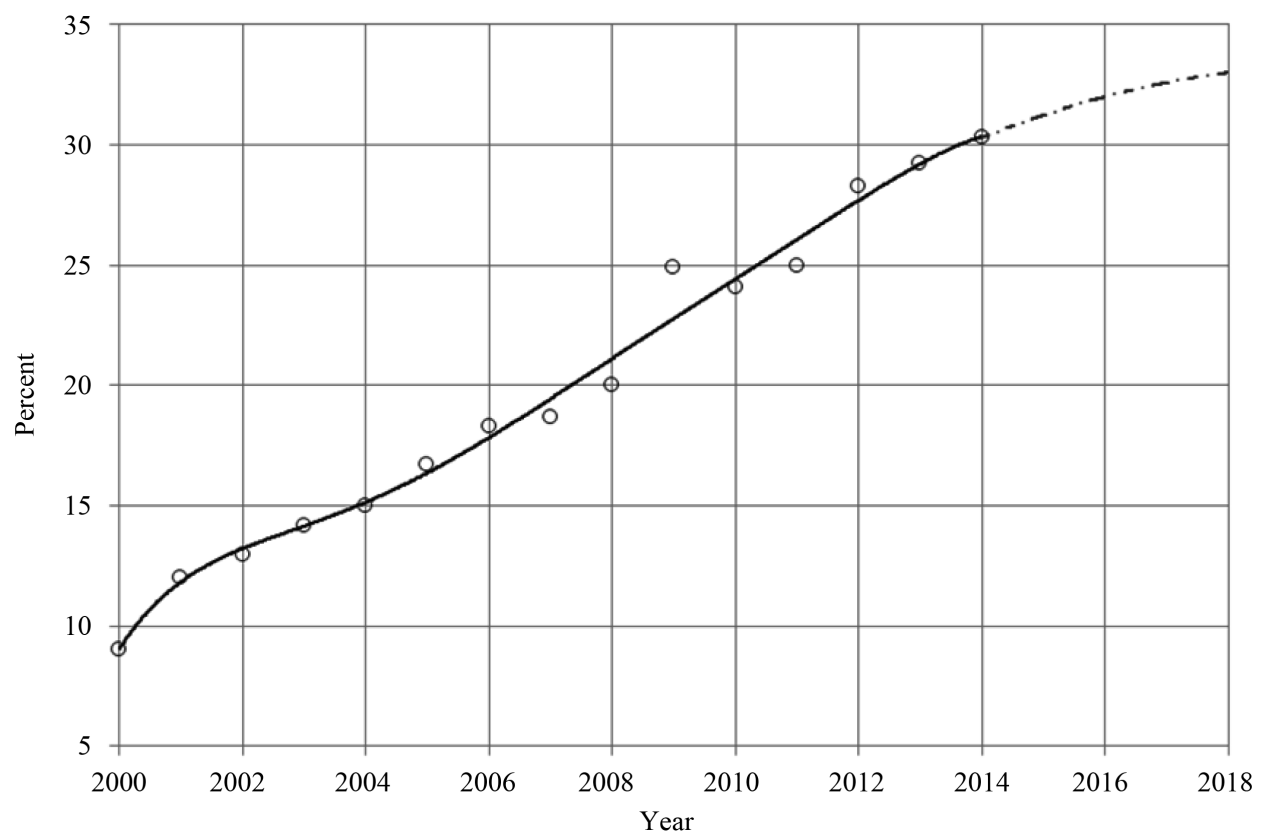

Figure 5. Fabless company IC sales as a percent of worldwide IC sales during 2000-2018; broken line show the projected fabless company IC sales as percent of global sales beyond 2014; data obtained from [21].

trends of IC sales, the extrapolated fabless company IC sales will reach about 33\% of total worldwide IC sales in the year 2018 [21]. Thus, fabless IC companies continue to gain market share.

The emerging trend in the microelectronics industry is that more IDMs are outsourcing their logic products to foundries and going fabless or fab-lite. The fabless companies create value with less capital investment as well as by establishing dominance in niche application rather than across applications. Three distinct business models have emerged in the fabless business segment [14]. 


\subsubsection{Innovator Fabless Business Model}

The fabless companies adopting innovator business model invest in continuous innovation for new applications, and they constantly expand their core intellectual property. Their efforts focus on unmet needs in the marketplace that come with large potential demand, and their explicit aim is to provide targeted IC chips at the scale required to recoup research and development costs. The innovator model is exemplified by leading companies like Qualcomm [22].

\subsubsection{Fast-Follower Fabless Business Model}

The fast followers do not invest capital on new market potential. Instead these companies pick large, rapidly growing markets and quickly develop Intellectual Property to enter in certain segments. They position themselves as presenting an integrated solution that is a lower-cost alternative to the market leader, with a streamlined business structure. Broadcom [23] has been an example of a fast follower fabless company.

\subsubsection{Mature-Market Attacker Fabless Business Model}

These companies wait until an application area has reached significant global volume before entering the competition. At that point, they attack the market with a simplified value-for-money product offering. Execution excellence, that is, efficient development and speedy production is crucial for such companies. The mature-market attacker companies include Mediatek [24], Monolithic Power Systems [25], Richtek Technology [26], MStar Semiconductor [27], and RDA Microelectronics [28].

With the ongoing commoditization of front-end manufacturing services and better access to the leading-edge intellectual property, the fabless industry will profit from its focused business system. The fabless segment will dominate in more and more successful applications, especially in consumer electronics and some areas of Information Technology.

\subsection{Front-End Manufacturing}

In the early days of foundry business model, the dedicated foundries, primarily, adopted advanced process technologies from the technology leading IDMs, qualified the technologies at the foundry fabs, and provided low cost manufacturing services to fabless customers as shown in Figure 6(a). By the mid-2000s, the process technology from the leading foundries reached parity with the leading-edge IDMs in standard CMOS technologies,

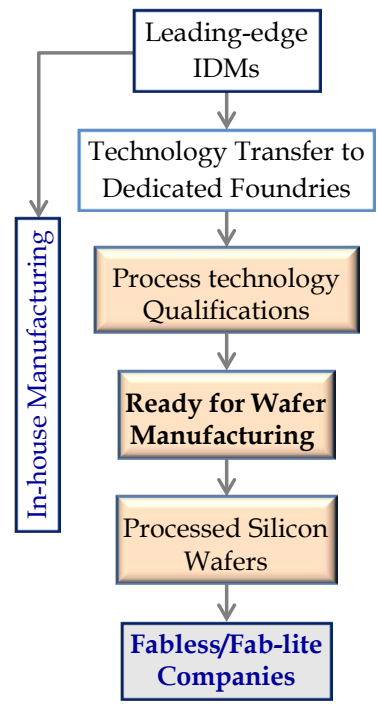

(a)

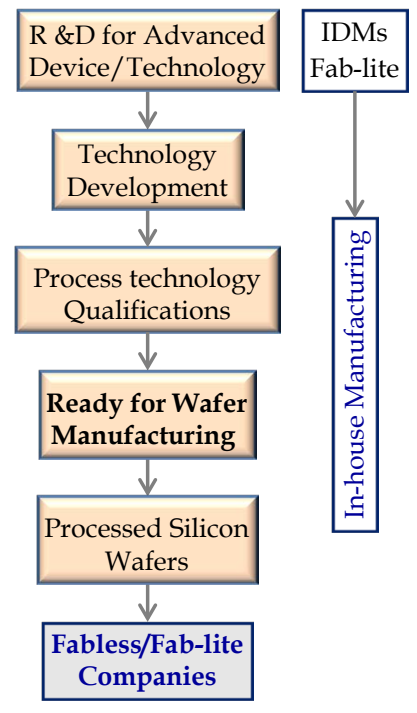

(b)

Figure 6. Front-end manufacturing trends: (a) IDMs as the leader in the early days of IC manufacturing; (b) emerging trend in the frontend manufacturing showing foundries as the leader providing wafer fabrication for fables and fab-lite companies with in-house leadingedge IC fabrication technology. 
e.g. TSMC's $28 \mathrm{~nm}$ CMOS technology developed independently at TSMC equals the highest achievable standard as that developed by IDMs such as Intel and Samsung. By the end of the 2000s, foundries became the core of new technology clusters; e.g. CMOS: low voltage, standard, and high voltage; Memories: Flash, Static Random Access Memory, etc., and so on [29]-[35]. Besides, foundries co-develop novelty technologies with fabless customers; e.g. TSMC developed different generations of split-gate flash memory technology with Silicon Storage Technology [32] [33]. Leading foundries like TSMC has developed core competencies in technology development and solving different physical effects in the scaled devices of today's CMOS technologies [15] [16].

Over the past several years, many IDMs have decided to step out of some aspects of the capital-intensive, leading-edge front-end technology development and fabrication part of the value chain. And, nearly all IDMs have outsourced some of their logic production to dedicated foundries and became fab-lite. Thus, the most of the front-end manufacturing in the microelectronics industry, today, is outsourced to foundries. Figure 6(b) shows the emerging trend in the front-end manufacturing where foundries are leading the bulk of the business. As a result, the foundry business has surged over the last decade [6]-[9]. With the advanced technologies, the emerging trend in manufacturing is that the foundries are aggressively competing for customers because of the high cost of advanced technology development. As a result, the price competition in this segment of the microelectronics industry value-chain is intensifying [14]. The foundry business model started the evolution in the IC business by separation of design and manufacturing. Microelectronics industry, which had represented the essence of advanced technology in the past, is becoming more commoditized, and competition within any given segments of the microelectronics value chain is continuously increasing.

\subsection{Back-End Manufacturing}

In the 1980s, IDMs relocated packaging plants in the Asia-Pacific region [16]. However, with the emergence of foundry business model, outsourcing of packaging business emerged in the early 1990s [13]. In the recent years, outsourced packaging business has accelerated with proliferation of customized and application-specific packaging demands with more than 130 Semiconductor Assembly and Test companies in the greater Asia-Pacific region. Currently, the Outsourced Semiconductor Assembly and Test (OSAT) activity is about \$25B business [13] [14].

In the early 1990s, the OSAT companies were regarded as low-end, commoditized service business, and the competitive dynamics of the business were driven by price competition [13]. However, with today's SoC packaging, the emerging trends show two profitable segments:

- The very profitable high-end companies providing miniaturized package;

- The mainstream OSAT companies providing legacy packages such as ASE group, Amkor Technology, and so on [36] [37].

As the pace of innovation slows in the front-end segment of the microelectronics value-chain, the emerging trend in the OSAT business is to offer sophistication and technical differentiation in a bid to increase SoC performance. Technological differentiation will continue to drive the two-tier market structure: there will be oligopolistic high-end companies and commoditized mainstream firms. Thus, with the shift of technology to OSAT business, this segment of the microelectronics industry is transitioning to provide miniaturized packaging solution for advanced-node SoCs.

\section{Discussions}

The microelectronics industry has been continuously evolving since the invention of ICs. In the early days, IDMs gained competitive advantage by developing state-of-the-art fabrication technology and manufacturing products using the technology at the firm's in-house fab. The slowing down in the progress along Moore's Law as the CMOS device dimensions approach their ultimate physical limit, the dynamics have changed from a strong and almost sole focus on process-technology development to a more diverse set of success factors including additional value-added services, operational performances and responsiveness, intellectual property, and cost management.

The foundry business model started the evolution in the IC business by separating design and manufacturing. Due to foundries, the IC industry which had represented the essence of advanced technology in the past has become more commoditized technology from foundries. The emerging trends in IC industry include: the foundries transitioning from pure-play manufacturing-only solution to complete IC new product development solution 
providers; fabless companies are focusing on strategies to design and sale niche products along with distinctive market-entry strategies; more IDMs are transitioning to fab-lite or fabless; foundries are taking complete control of front-end manufacturing and state-of-the-art technology development; and back-end OSAT companies are in competition to provide scaled packaging solutions to customers. The competition within any given segment of the microelectronics value chain is continuously increasing leading to the transition of the respective business model.

Looking ahead, the microelectronic industry will continue to evolve in providing solutions for emerging smart-electronic products for self-driving or driverless cars, smart city infrastructure, Internet of Things, and so on. One of the major drivers in transitioning the industry is automobile industry for mass production of driverless cars. The driverless cars require gigabit-memories, a large number of sensors, entertainment systems, and so on integrated into an electronic system for mobility as well as electronic and social networking. The sensors are to provide road-safety such as maintaining a safe distance between cars in front and back, automatic breaking system, maintaining speed limit, identifying and reacting on road and weather conditions, and so on. And, to facilitate the driverless cars on the road and highways, the smart city infrastructure with urban analytics and modeling processes must be established. The smart city infrastructure for driverless cars includes smart electronic systems along with software codes to communicate cars and urban traffic system for the safety of drivers and pedestrians and maintaining echo systems.

\section{Conclusion}

The present study shows that the major business sectors of the microelectronics industry will continue to evolve to provide solutions for driverless cars and smart city infrastructure by acquiring core competencies in manufacturing smart and durable electronic systems. The foundry business model will evolve by acquiring competencies in durable new materials for manufacturing IC chips for driverless cars, active engagement with the automotive industry and city governance in establishing standards and requirements for driverless cars, and testing for reliability, durability, and safety of driverless automobiles; the fabless design houses will continue transitioning by acquiring competencies in design for reliability, durability, and safety, and acquiring relevant knowledge on the dependable and robust software codes in collaboration with the electronic design automation companies; and the back-end manufacturer will acquire core competencies in advanced packaging materials and packaging technology for providing durable IC chips for automotive applications in extreme environmental conditions and smart city infrastructure.

\section{References}

[1] Kilby, J.S. (1964) Miniaturized Electronics Circuits. US Patent 3138743.

[2] Kilby, J.S. (1976) Invention of the Integrated Circuit. IEEE Transactions on Electronic Devices, 23, 648-654. http://dx.doi.org/10.1109/T-ED.1976.18467

[3] Saha, S.K. (2013) Introduction to Technology Computer Aided Design. In: Sarkar, C.K., Ed., Technology Computer Aided Design: Simulation for VLSI MOSFET, CRC Press, Taylor \& Francis Group, Boca Raton. http://dx.doi.org/10.1201/b14860-2

[4] Moore, G.E. (1965) Cramming More Components onto Integrated Circuits. Electronics, 38,114-117.

[5] Perry, T.S. (2011) Foundry Father. IEEE Spectrum, 48, 46-50. http://dx.doi.org/10.1109/MSPEC.2011.5753245

[6] Taiwan Semiconductor Manufacturing Company (TSMC). http://www.tsmc.com/

[7] United Microelectronics Corporation (UMC). http://www.umc.com/

[8] Silterra Malaysia (Silterra). http://www.silterra.com/

[9] Globalfoundries. http://www.globalfoundries.com/

[10] Saha, S.K. (2001) Semiconductor-Foundries for Customer-Specific IC Manufacturing Technology Development. Proceedings of the IEMC'01, 124-129. http://dx.doi.org/10.1109/iemc.2001.960496

[11] Saha, S.K. (2010) The Role of Product Development Technology Group in the Global Semiconductor Foundry Business Model. Proceedings of PICMET'10, Technology Management for Global Economic Growth (PICMET), Phuket, 18-22 July 2010, 1-4.

[12] Saha, S.K. (2012) The Role of Semiconductor Foundries in Advanced Integrated Circuit Product Development. 2012 IEEE International Technology Management Conference (ITMC), Dallas, 25-27 June 2012, 32-35. 
http://dx.doi.org/10.1109/itmc.2012.6306393

[13] Vagues, M.V. and Kumar, S. (2012) Transitioning Semiconductor Foundry Business Model to Complete IC Manufacturing Turnkey Solution Provider. Proceedings of PICMET'12, Technology Management for Emerging Technologies (PICMET), Vancouver, 29 July-2 August 2012, 2754-2757.

[14] Naehrer, U., Suzuki, S. and Wiseman, B. (2011) The Evolution of Business Models in a Disrupted Value Chain. http://www.mckinsey.com/client_service/semiconductors/latest_thinking/the_evolution_of_business_models_in_a_disr upted_value_chain

[15] Tseng, F.C. (1996) Foundry Technologies. International Electron Devices Meeting, IEDM '96, San Francisco, 8-11 December 1996, 19-24. http://dx.doi.org/10.1109/iedm.1996.553030

[16] Sun, J.Y.-C. (1998) Foundry Technology Trend. Proceedings of SPIE, 3506, 19-24. http://dx.doi.org/10.1117/12.323970

[17] Saha, S.K. (2013) Emerging Business Trends in the Semiconductor Industry. Proceedings of PICMET'13, Technology Management in the IT-Driven Services (PICMET), San Jose, 28 July-1 August 2013, 2744-2748.

[18] Global Semiconductor Alliance (GSA). https://www.gsaglobal.org/gsa-resources/publications/ic-foundry-almanac/

[19] Armstrong, G.A. and Maiti, C.K. (2007) Technology Computer Aided Design for Si, SiG and GaAs Integrated Circuits. The Institution of Engineering and Technology, Stevenage.

[20] Li, S. and Fu, Y. (2012) 3D Technology CAD Simulation for Semiconductor Processes, Devices and Optoelectronics. Springer, Berlin. http://dx.doi.org/10.1007/978-1-4614-0481-1

[21] IC Insights. http://www.icinsights.com/

[22] Qualcomm. https://www.qualcomm.com/

[23] Broadcom. https://www.broadcom.com/

[24] Mediatek. http://www.mediatek.com/

[25] Monolithic Power Systems, Inc. https://www.monolithicpower.com/

[26] Richtek Technology. http://www.richtek.com/

[27] Mstar Semiconductor. http://www.mstarsemi.com/

[28] RDA Microelectronics. http://www.rdamicro.com/

[29] Saha, S. (2001) Design Considerations for 25 nm MOSFET Devices. Solid-State Electronics, 45, 1851-1857. http://dx.doi.org/10.1016/S0038-1101(01)00197-6

[30] Plummer, J.D., Deal, M.D. and Griffin, P.B. (2000) Silicon VLSI Technology: Fundamentals, Practice and Modeling. Prentice Hall, Upper Saddle River.

[31] Saha, S.K. (2002) Transistors Having Optimized Source-Drain Structures and Methods for Making the Same. US Patent No. 6344405.

[32] Kianian, S., Levi, A., Lee, D. and Hu, Y.-W. (1994) A Novel 3 Volts-Only, Small Sector Erase, High Density Flash E2PROM. 1994 Symposium on VLSI Technology, 1994. Digest of Technical Papers, Honolulu, 7-9 June 1994, 71-72.

[33] Saha, S.K. (2007) Design Considerations for Sub-90 nm Split-Gate Flash Memory Cells. IEEE Transactions on Electron Devices, 54, 3049-3055. http://dx.doi.org/10.1109/TED.2007.907265

[34] Kuhn, K.J., Giles, M.D., Becher, D., Kolar, P., Kornfeld, A., Kotlyar, R., Ma, S.T., Maheshwari, A. and Mudanai, S. (2011) Process Technology Variation. IEEE Transactions on Electron Devices, 58, 2197-2208. http://dx.doi.org/10.1109/TED.2011.2121913

[35] Saha, S.K. (2010) Modeling Process Variability in Scaled CMOS Technology. IEEE Design \& Test of Computers, 27, 8-16. http://dx.doi.org/10.1109/MDT.2010.50

[36] ASE Group. http://www.aseglobal.com/

[37] Amkor Technology. http://www.amkor.com/ 